\title{
Illusory contours: On the efficacy of their need for expression
}

\author{
THEODORE E. PARKS \\ University of California, Davis, California
}

When an illusory-figure pattern is presented against a physical lightness gradient, the illusory figure's lightness relative to the surround is often the reverse of the usual effect, a fact that suggests that, rather than the figure's depending upon illusory lightness, real lightness differences can be utilized in its expression. A second demonstration suggests that the apparent strength of the lightness effect may be greater where there is relatively less physical expression of the contour. Again, the establishment of the contour seems to involve more than merely "capturing" illusory lightness.

It has been widely reported that the illusory lightness alteration which typically accompanies an illusory figure of the type introduced by Schumann (1904) and further developed by Ehrenstein (1941) and Kanizsa (1955) will be drastically reduced when the area of that figure is outlined with thin lines (e.g., Coren \& Theodor, 1975; Ehrenstein, 1941; Kennedy, 1979; Spillmann, 1975). In fact, this loss occurs even when those added lines do not touch (and, therefore, do not alter the configuration of) any of the elements that induce the illusory figure (Parks, 1979). Such results suggest that, in the absence of relatively complete physical contours, advantage is taken of any tendencies toward lightness alteration that happen to be present in order to achieve perceptual expression of a suggested contour. For example, diffuse illusory lightness effects (ones that would not, of themselves, produce a stepwise gradient at the edges of the illusory figure) might be transformed into an apparently abrupt gradient, as needed, in order that the illusory contour be perceptually realized.

The present report describes support for this possibility in the form of two rather surprising, but highly instructive, phenomena.

\section{EXPERIMENT 1}

If it is supposed that diffuse illusory differences in lightness can be recruited and modified to achieve an abrupt illusory contour, then it might be expected that real (physical) differences, when present, might be similarly employed. Consider, for example, Figure 1 a. Typically, an inducing pattern that consists of black elements on a uniform light field induces the impression

The author would like to thank Margo Reardon and Marie Nomura for their assistance in collecting the present data. This research was supported by Grant D-262 from the University of California, Davis. The author's complete mailing address is: Department of Psychology, University of Calitornia, Davis, California 95616
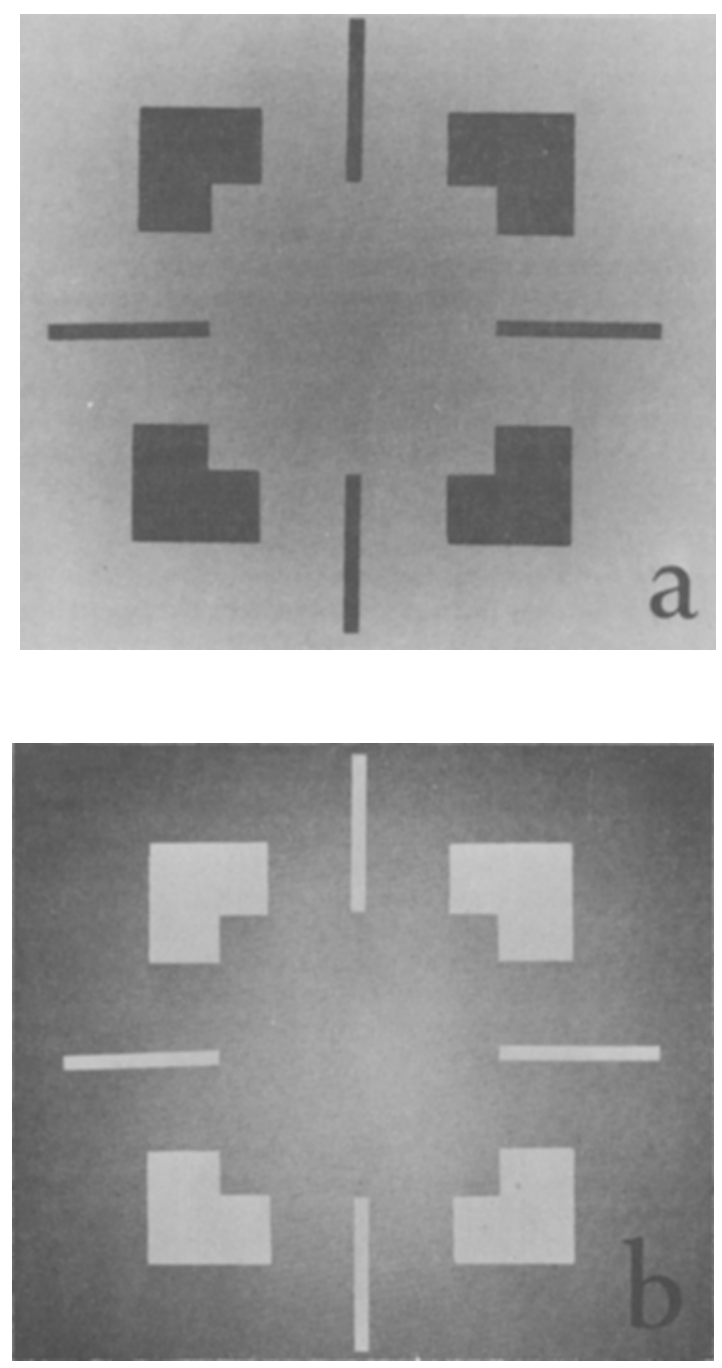

Figure 1. The two stimulus patterns employed in Experiment 1 . On homogeneous backgrounds, pattern (a) would be expected to induce a relatively light illusory figure, while (b) would be expected to produce a dark one. 
of an illusory figure that is lighter than the surround (i.e., the contours appear to consist of a step-down in apparent lightness from within to without). In Figure 1a, on the other hand, the field is not uniform but is darkest at the center and gradually becomes lighter as one moves to the locale of the illusory contours and beyond. Might these smooth gradations in background lightness be employed and altered into the stepwise expression of the illusory contour and thereby tend to produce an incremental (rather than the usual decremental) stepwise illusory gradient?

\section{Method and Materials}

A group of 32 naive volunteers were individually shown Figures $l a$ and $1 b$, equally often in either order. As can be seen, the latter pattern consists of white elements, which would be expected to produce a dark illusory figure when presented on a uniformly dark field. In this case, however, the background is lightest at the center and gradually darker towards the periphery. By the same reasoning that was applied to Figure 1a, it was expected that this pattern might exhibit a tendency toward the production of a lighter-than-surround illusory square.

These patterns were $9 \mathrm{~cm}$ in height and were viewed at a distance of $2 \mathrm{~m}$ under normal room illumination. For Figure 1a, reflectance was approximately $17 \%$ at the center and smoothly increased to $22 \%$ at a point halfway to the illusory contour, to $27 \%$ at the locale of the contours, and to $31 \%$ at an equal interval outside the contour. For Figure 1b, these values were reversed.

When either stimulus pattern was presented, each of the subjects was specifically cautioned that the "square" in the middle of the pattern "might be hard to see" and "might come and go," was told to make a decision only when the square's edges could be seen "clearly," and was told especially to attend to and report on the square's "edges rather than its center." Each subject was then asked the following question: "When an edge seems sharp and clear, does it appear to be lighter or darker than the paper around it (just outside of it)?" Thus, first of all, care was taken to discourage trivial reports of the obvious lightness differences between the center of the background and its periphery. Second, it should be emphasized that these instructions explicitly asked that lightness judgments be made only when an abrupt illusory gradient was experienced, and thus discouraged trivial reports that a smooth physical gradient was present across the locale of those contours. In fact, no subject reported an inability to perceive clear illusory contours. Finally, it should be noted that the instructions referred to "edges," which, though technically incorrect (since that word refers to an infinitely narrow and, therefore, colorless boundary), was meant, of course, to refer to the areas just inside the boundaries. The context (especially the contrast, in the previous sentence, of the "center" of the square to "its edges") apparently made this usage clear to most of the subjects, since only six asked for clarification (and were told that the reference was to the areas just inside the boundaries) and none explicitly complained that the question was nonsensical. At any rate, the possibility that this wording was taken in the technical sense was evaluated in a subsequent group of 32 similar subjects who were shown a more typical illusory contour pattern (i.e., the black elements of Figure la but on a plain white background) with exactly the same instructions.

\section{Results and Discussion}

In all, 15 of the 32 observers reported darker-thansurround illusory edges in Figure 1a (that is, the opposite of the usual effect with black inducing elements).
Similarly, 15 of these subjects (but not always the same subjects) reported a relatively light illusory figure in response to the white elements of Figure $1 \mathrm{~b}$. These findings that the presence of physical brightness gradients produce almost equal proportions of lighter-than and darker-than reports are most striking when compared with the usual preponderance of one or the other effect. For example, of the 32 subjects who were shown the more typical (uniform background) version of Figure 1a, 28 reported that its edges appeared to be lighter than the surround, with this frequency being reliably different from that obtained with Figure la as shown here $\left[\chi^{2}(1)=7.50, p<.01\right]$. In the same vein, the literature contains no known reports of white inducing elements' yielding a "light" illusory figure.

It is important to note again that the lack of a clear preference in these reports cannot easily be attributed to a supposed understanding by the subjects that they were being asked to report on an infinitely narrow colorless "edge" and, therefore, had no choice but to respond randomly. As related above, a group that received exactly the same instructions with a more ordinary pattern clearly did not respond randomly. It appears, then, that the background gradients were effective and that, specifically, such brightness may be incorporated into the lightness gradients of the concurrent illusory figures. That they do not always predominate is not surprising, since they are in conflict with whatever those mechanisms are that produce the usual lightness effect (i.e., that which dominates when the background is homogeneous).

\section{EXPERIMENT 2}

The fact that an illusory contour may involve a stepwise alteration in an otherwise smooth gradient, even if the latter is physical, clearly indicates that the existence of such contours is not causally dependent upon illusory lightness effects. Such independence reaffirms the contention that, not only are illusory contours expressed by apparent stepwise gradients, but also those abrupt gradients are created for the purpose of that expression. This possibility leads to an additional, rather curious, prediction: it might be that, within a given illusory contour, the illusory lightness effect will be strongest in those places where that contour receives the least local physical support from the inducing elements. Consider, for example, the two halves of the upper edge of the illusory square that is induced by Figure 2. One half has no real support between its two ends (i.e., between the point at which it touches a corner element and the point at which it touches the central vertical line), while the other half has the additional definition supplied by the abrupt termination of the diagonal element midway along its length. Will, in fact, the apparent lightness effect be strongest in the former portion of the figure (which is to say, where it is needed more)? 


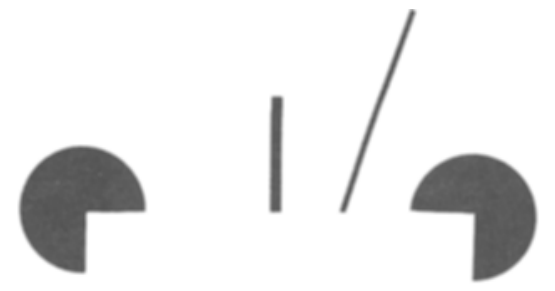

mans
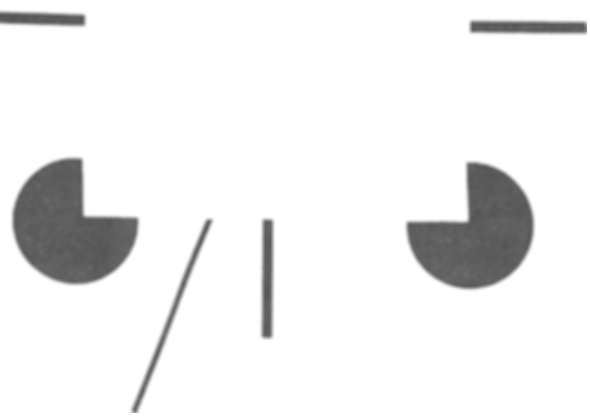

Figure 2. The pattern employed in Experiment 2.

\section{Method and Materials}

A total of 64 naive volunteers were individually shown, at a distance of $2 \mathrm{~m}$ and under normal room illumination, one of two 10-cm-high versions of the pattern depicted in Figure 2. Specifically, half of these subjects were shown the pattern as it appears here, while the remaining half were shown its mirror image.

In a pilot study, 16 subjects had been shown a similar pattern and had been asked to compare the two halves of the "upper edge" and, separately, the two halves of the "lower edge." Interestingly, 9 subjects reported that the unsupported portion appeared to be the lighter of the two halves in both cases, while only 2 chose both supported halves (the other subjects choosing one of each type). However, it was feared that the instructions might have been misunderstood and that these reports reflected an impression (perhaps due to the presence of the black line) that the background appeared darker just outside of the supported edge (in other words, the fear was that these pilot subjects had reported on the "edges" of the background rather than on the edge of the illusory square itself). As a result, the instructions for the present experiment emphatically and explicitly asked for reports on the "edge of the square." As in the pilot study, each subject was asked to compare the two halves of the upper illusory contour and, separately, of the lower contour; this was done equally often in either order, across subjects, with either form of Figure 2. Specifically, in each case they were asked to indicate which half appeared to be the lighter or brighter.

\section{Results and Discussion}

Of the 64 subjects tested, 45 (i.e., 70\%) chose the unsupported half of the upper contour as being lighter $\left[\chi^{2}(1)=10.56, p<.01\right]$. Similarly, 41 subjects $(64 \%)$ chose the unsupported half of the lower edge $\left[\chi^{2}(1)=\right.$ $5.06, p<.05]$. Thus, overall, unsupported halves were favored in a nearly two-to-one majority of cases.

These results are a clear and important variance from those theories of illusory contour lightness that propose that its source lies in diffuse "buttons" of contrast formed off the ends of such elements as the thin lines of Figure 2, which "buttons" then merely spread to all parts of the illusory contour (e.g., Frisby \& Clatworthy, 1975; Kennedy \& Lee, 1976). According to such theorizing, of course, the lightness effect in each unsupported half should, at most, equal that of the supported half. In fact, not only were the actual choices reliably deviant from chance (from equality), but the majority actually favored the sides that did not have a central supporting "button." If such buttons are, indeed, the source of the present illusory lightness, then the suggestion must be that not only are those effects spread and altered into stepwise illusory contours, but there is also some tendency towards those effects' being relatively enhanced to the inside of the relatively unsupported portions of those contours.

This is not to say that no limit is expected as to the extent to which illusory lightness will spread and be enhanced to express a contour. It is known that shorter illusory contours are reported as being more "vivid" or "readily seen" than longer ones (Brigner \& Gallagher, 1974) and as having more "strength" or "salience" (Dumais \& Bradley, 1976). Thus, even though these researchers did not directly query their subjects with respect to apparent lightness, it is reasonable to expect that an otherwise very poorly supported contour might not elicit a great deal of support from such a lightnessenhancing mechanism. For instance, it might be of importance that the present unsupported halves were each part of a continuous illusory contour that was relatively well supported in its other half. In other words, it may be that the system spreads and enhances illusory lightness "buttons" only when (and only to the degree that) expression is required for a contour that is, for the most part, fairly well supported by other (physical) information.

At any rate, regardless of the ultimate source of the illusory lightness seen in patterns such as these, both of the present experiments add weight to the suggestion that the need to perceptually express an illusory contour plays a causative role in its production.

\section{REFERENCES}

Brigner, W. L., \& Gallagher, M. B. Subjective contour: Apparent depth or simultaneous brightness contrast? Perceptual and Motor Skills, 1974, 38, 1047-1053.

Coren, S., \& Theodor, L. H. Subjective contour: The inadequacy of brightness contrast as an explanation. Bulletin of the Psychonomic Society, 1975, 6, 87-89.

Dumais, S. T., \& Bradiey, D. R. The effects of illumination level and retinal size on the apparent strength of subjective contours. Perception \& Psychophysics, 1976, 19, 339-345.

Ehrenstein, W. Über abwandlungen der L. Hermannschen helligkeitserscheinung. Zeitschrift für Psychologie, 1941, 150, 83-91.

Frisby, J. P., \& Clatworthy, J. L. Illusory contours: Curious cases of simultaneous brightness contrast? Perception, 1975, 4, 349-357. 
Kanizsa, G. Margini quasi-percettivi in campi con stimolazione omogenea. Rivista di Psicologia, 1955, 49, 7-30.

KENNEDY, J. M. Subjective contours, contrast, and assimilation. In C. F. Nodine \& D. F. Fisher (Eds.), Perception and pictorial representation. New York: Praeger, 1979.

KenNeDY, J. M., \& LEe, H. A figural-density hypothesis and illusory contour brightness. Perception, 1976, 5, 387-392.

Parks, T. E. Subjective figures: Does brightness enhancement depend upon subjective boundary definition? Perception \& Psychophysics, 1979, 26, 418.
Schumann, F. Einige beobachtungen über die zusammenfassung von gesichtseindrucken zu einheitne. Psychologische Studien, 1904, 1, 1-32.

SpillmanN, L. Perceptual modification of the Ehrenstein illusion. In S. Ertal, L. Kemmler, \& M. Stadler (Eds.), Gestalttheorie in der modernen Psychologie. Darmstadt: Steinkopff, 1975.

(Manuscript received March 15, 1982;

revision accepted for publication July 14, 1982.) 